\title{
The Neural Correlates of Product Attachment to Cosmetics: Is It Similar to That of Attachment in Human Relationships?
}

Yoshiaki Kikuchi ( $\sim$ ykikuchi@tmu.ac.jp )

Tokyo Metropolitan University

Madoka Noriuchi

Tokyo Metropolitan University

Hiroko Isobe

Shiseido Global Innovation Center

Maki Shirato

Shiseido Global Innovation Center

Naoyasu Hirao

Shiseido Global Innovation Center

\section{Research Article}

Keywords: cosmetics, primary somatosensory cortex, oxytocinergic activities, functional magnetic resonance imaging

Posted Date: January 18th, 2021

DOl: https://doi.org/10.21203/rs.3.rs-145584/v1

License: (c) (i) This work is licensed under a Creative Commons Attribution 4.0 International License. Read Full License 


\section{Abstract}

We used functional magnetic resonance imaging to investigate the similarities in the attachment toward individual's favorite cosmetics and beloved person, both of which are reinforced by touch-driven behaviors. We conducted 2 (visual and visual with tactile) $\times 2$ (preferred and non-preferred cosmetics) experiments. Thereafter, we set regions of interest as per previous studies of human relationship attachment and tested their significance. The hippocampus, posterior cingulate cortex (PCC), putamen, periaqueductal gray (PAG), dorsal raphe nucleus (DRN), and ventral tegmental area were activated in the visual with tactile session, but not in the visual session, revealing that common brain regions are activated in human relationship attachment and attachment to cosmetics, and that tactile cue is important for attachment to cosmetics. Moreover, the PAG showed an interactive effect between tactile cue and preference, and the DRN positively correlated with "security" feeling associated with attachment. Activity in these regions was positively correlated with activity of the PCC and primary somatosensory cortex. This suggests that tactile discriminative cues induce the individual's autobiographical memories of using the cosmetics daily, and the DRN and PAG are activated in association with these memories. These serotonergic and oxytocinergic activities may be critical for the maintenance of attachment to cosmetics.

\section{Introduction}

Several qualitative and survey studies on consumer-product attachment have concluded that the degree to which a product is used to define and maintain a persons' self-image affects not only the preference, but also the experience of an emotional bond to the product during ownership [1-4]. Product attachment is defined as the strength of the emotional bond experienced by the owner towards a product when the specific product bears significant meaning to the owner [5]. Most people experience positive emotions toward the product to which they feel attached [6]; they feel more attached to products that are used to define and maintain themselves $[2,3,6]$. In addition, memories contribute positively to the degree of attachment, and the attachment is correlated with the irreplaceability of the product [7]. Research on human relationships have revealed several similarities between human attachment experience in relationships and product attachment $[5,8]$. Among the attachments experienced to different types of products, attachment to cosmetic products may particularly be similar to human relationship attachment in some aspects. Self-concept is an important factor for positive relationships in human attachment [9]. The use of cosmetics is one way by which individuals can define and express their unique selves, as observed in human attachment in relationships [10]. People may use cosmetics to define themselves and create a sense of identity, as a reminder of who they are or ought to be like, and to protect and enhance their self-concept, as in the case of human attachment in relationships [1,3,4]. Moreover, the attachment to cosmetic products is considered to develop through touch-driven bonding behaviors, which are critical for the establishment and maintenance of human attachment in relationships. It is well known that skinto-skin contact promotes attachment between the infant and his/her caregiver [11]. Cosmetic users gently take care of their faces while applying their favorite cosmetics, using their own fingers, particularly while 
following their daily skincare regimen. Such behaviors are, therefore, considered to reinforce the bond between the user and his/her favorite cosmetics, and this intimate relationship may establish a specific attachment to the cosmetic product.

A number of neuroimaging studies of the human attachment behavior system have been conducted thus far, which have revealed the central roles of the dopaminergic, serotonergic, and oxytocinergic systems $[12-15,26]$ (Table 1). Furthermore, these studies have shown similarities and differences in the brain activity between early stage [13] and long-term romantic love [14,15]. While the brain regions involved in the dopaminergic reward system, including the substantia nigra/ventral tegmental area (SN/VTA), are commonly activated in both phases of love, serotonergic activity in the dorsal raphe nucleus (DRN) was found in long-term romantic love [14,15], but not in early stage romantic love [13]. This finding supports the view that long-term romantic love is characterized by security and calm [16], whereas early stage romantic love is characterized by insecurity and stress [16,17]. Furthermore, brain activity in long-term romantic love has been shown to be similar to that observed in maternal love [14,18-22]. Thus, neuroscientific research on human attachment in relationships has provided important findings on the neural basis of diverse human attachments in relationships. It is critical to identify the neural basis of attachment to cosmetics for understanding neural correlates that play a role in evaluative judgments and decision-making processes in neuroeconomics [23], and to better evaluate hoarding disorder involved in emotional attachment to possessions in psychiatry [24, 25]; however, no such study has evaluated these aspects. Accordingly, we investigated the neural substrate for attachment to cosmetics by using functional magnetic resonance imaging (fMRI). The present study was the first neuroimaging study to investigate the neural substrate for attachment to cosmetics. First, we hypothesized that the users would show similar brain responses to the cosmetic products to which they felt attached, as observed in previous $\mathrm{fMRI}$ studies of human attachment in relationships. Second, we hypothesized that the brainstem regions, such as the DRN and periaqueductal gray (PAG), which were identified in long-term human attachment in relationships would play important roles in attachment to cosmetics because these regions, which are rich in important neurotransmitters, may play a role in the establishment, promotion, and maintenance of the secure relationships between the user and his/her favorite cosmetic products. Third, we hypothesized that tactile and memory information processing would play an important role in building and maintaining attachment to cosmetics because these are considered to be reinforced through daily touch-driven bonding behaviors and memorized in the individual's autobiographical memories.

To test these hypotheses, we recruited loyal users who had been using one of the three kinds of face serums for a period that was considered long to some extent. All of these face serums were manufactured by famous and long-time sellers of luxury brands worldwide. In addition, we checked whether the participants were actually attached to their specific face serum by subjective evaluations. Moreover, we performed an fMRI experiment in two different sessions: the visual session and the visual coupled with the tactile session. Each session consisted of two conditions: the preferred cosmetic condition and the non-preferred cosmetic condition. Further, we set the regions of interest (ROIs) based on the brain regions identified in the previous fMRI studies of human attachment in relationships [13-15, 26], and the activity in each of the ROls was tested by using the small volume correction (SVC) test. In 
addition, we explored the relationship between these brain regions and the subjective feeling associated with the feeling of attachment. Moreover, we set the additional somatosensory-related ROIs identified in our previous studies $[27,28]$, and investigated the effects of tactile information processing and preference by comparing these brain activities in the visual with tactile session to those in the visual session. Thereafter, we assessed the correlation between the activity in each brainstem region and activities in each of the memory-related ROls and the somatosensory-related ones.

\section{Results}

Among the preferred and non-preferred cosmetics, the scores of subjective evaluations showed significant differences for "security" $(t=5.2, p=0.000053)$ and "attachment" $(t=5.9, p=0.000010)$, whereas those for the other test items were not significant ("positive feeling of texture," $t=1.8, p=0.097$; "expectation for skincare effect," $t=2.2, p=0.044$; "want to buy," $t=2.5, p=0.022$; "satisfaction" $t=2.7, p$ $=0.014$ ) (Fig. 1). Moreover, the multiple regression analysis showed that "security" showed a significantly positive correlation with "attachment" $\left(t=3.6, p=0.0020 ; R^{2}=0.42 ;\right.$ Durbin-Watson [D-W] statistic = 2.0; Shapiro-Wilk [S-W] test $p=0.39$ ) in the preferred cosmetic condition (Fig. 2), whereas no significant correlation was observed in the non-preferred cosmetic condition.

In the visual with tactile session, the ROI analysis showed that the posterior cingulate cortex (PCC) (3 -22 29) $(p=0.018$, family-wise error [FWE]; $[13,26])$, left $(-40-36-12)$ and right $(40-31-4)$ posterior hippocampus ( $p=0.027$ and 0.021 , FWE, respectively; [26]), right putamen (29 $2-3)(p=0.025, F W E ;[26])$, left (-4 -22 32) and right (6 -16 32) PCC ( $p=0.025$ and 0.0090, FWE, respectively; [15]), DRN (6 -32 -24) ( $p$ $=0.041$, FWE; $[14,15])$, PAG (3 -35 -28) ( $p=0.034$ FWE; $[14,15])$, and SN/VTA $(4-20-16)$ ( $p=0.047$, FWE; [14]) were significantly activated, as shown in Table 2 and Fig. 3. On the other hand, there was no significant activity in the visual session (Table 2). Moreover, the DRN showed a significantly positive correlation with "security" feeling in the visual with tactile session $\left(t=2.5, p=0.024 ; R^{2}=0.25 ; D-W\right.$ statistic $=2.4 ; \mathrm{S}-\mathrm{W} \mathrm{p}=0.39$ ); however, there was no significant correlation between them in the visual session (Fig. 4). Among all ROls, including the somatosensory-related regions, the PAG was found to have a significant interactive effect between the conditions and sessions $(F=5.6 ; p=0.029)$, and the PAG activity was significantly greater with the preferred cosmetics than with the non-preferred ones in the visual with tactile session $(t=2.7 ; p=0.014<0.025=0.05 / 2)$ (Fig. 5 a); however, there was no significance in the visual session $(t=0.67 ; p=0.51)$. In addition, there were significant main effects of sessions observed in each of the somatosensory-related ROIs (Fig. 5 b, c, d, e). These regions showed greater activity in the visual with tactile session than in the visual session. Moreover, there were significant main effects of conditions observed in the right PCC (6 -16 32) and the left PCC (-4 -22 32) (Fig. $5 \mathbf{f}, \mathbf{g}$ ), and these brain regions showed greater activity in the preferred conditions than in the nonpreferred conditions. Furthermore, the multiple regression analysis revealed that each of the DRN $(t=2.9$, $p=0.0099<0.025=0.05 / 2, R^{2}=0.46, D-W$ statistic $\left.=2.3, S-W p=0.35\right)$ and PAG $(t=2.5, p=0.024<$ $0.025=0.05 / 2, R^{2}=0.42, D-W$ statistic $\left.=2.1, S-W p=0.35\right)$ positively correlated with the PCC (6 -16 32) (Fig. 6 a, b), and the SN/VTA positively correlated with the PCC $(-42232)(t=2.7, p=0.014<0.025=$ 
$0.05 / 2 ; R^{2}=0.25 ; D-W$ statistic $\left.=2.1 ; S-W p=0.15\right)$. In addition, the multiple regression analysis showed that the right primary somatosensory area (SI) showed a significantly positive correlation with each of the $\operatorname{DRN}\left(t=2.3, p=0.034<0.05, R^{2}=0.23, D-W\right.$ statistic $\left.=2.3, S-W p=0.11\right)$ and PAG $(t=2.2, p=0.038<$ $0.05, R^{2}=0.22$, D-W statistic $\left.=2.1, S-W p=0.11\right)(F i g .6 c, d)$. There was no significant correlation in the SN/VTA.

\section{Discussion}

This study investigated the neural correlates of attachment to cosmetic products using $\mathrm{fMRI}$ and subjective evaluations. The brain activity in response to visual with tactile stimuli related to the cosmetic product to which the participant was attached was assessed in the brain regions that have been previously implicated in the feeling of attachment experienced in human relationships. Thus, we demonstrated that several brain regions that are involved in attachment in human relationships are also involved in attachment to cosmetic products.

Analysis of the subjective evaluations showed that the score of "attachment" was significantly higher for the preferred cosmetics than for the non-preferred ones, showing that our participants felt stronger attachment to their preferred cosmetics than to the others. Moreover, the feeling of "security" was significantly stronger for the preferred cosmetics than for the non-preferred ones, and positively correlated with the feeling of "attachment." These results are supported by a psychological study, which has shown "security" to be one of the most important factors in product attachment [29]. In the visual with tactile session, several brain regions, including the brainstem regions, were significantly activated in response to the preferred cosmetics than to the non-preferred ones when assessed by the SVC test. This result showed that the brain response to the cosmetics to which our participants felt attachment was, at least partly, similar to that identified in the attachment experienced in human love relationships [13-15,26]. That is, we showed here that there exists some common brain activity between human attachment and product attachment to cosmetics. It should be noted that the brainstem regions, such as the DRN, PAG, and SN/VTA, that have been identified to be involved in long-term attachment relationships (Table 2) $[14,15]$ were found to be significantly activated in the case of attachment to cosmetics. These regions have been further identified to be activated by maternal love [18], and are the primary sites of neurotransmitters that modulate the basic functions of survival, such as reward/motivation, positive emotion, and the maintenance of secure states [12]. Accordingly, it is interesting that these regions may also play a key role in the establishment, promotion, and maintenance of secure relationships between the user and his/her preferred cosmetics. The SN/VTA is centrally placed in a wider motivational/reward network associated with behaviors necessary for survival [30-32]. Findings from diverse fMRI studies of romantic love provide strong evidence that the dopaminergic reward system, including the SN/VTA, is widely associated with the different forms of human love attachment (early stage to long-term romantic love, and maternal love). The ROI of SN/VTA that was significantly activated in the present study was the one that has been identified to be activated in long-term attachment [14], but not in the early-stage romantic relationships [13] (Table 2). This result suggests that there is a rather different functional 
localization within the SN/VTA region. The DRN also plays a pivotal role in reward processing. DRN neurons show a tonic firing pattern in response to expected and received reward values, whereas SN/VTA neurons exhibit phasic responses related to reward prediction errors. The DRN is a serotonin-rich site, and serotonin is implicated in love and pair bonding [33]. Moreover, serotonin is a critical neuroendocrine factor involved in several psychiatric disorders, including obsessive-compulsive disorder [34], depression [35], eating disorders [36], and anxiety disorders [37]. Our previous finding [15] showing that DRN activity negatively correlated with attachment-related anxiety suggested that DRN plays an important regulatory role in anxiety and insecurity associated with human attachment relationships, even in healthy people. Security is one of the set goals of the attachment system [16]. Furthermore, a psychological study also showed that "security" was one of the most critical factors in product attachment [6]. These findings support the present result that the DRN activity was positively correlated with the feeling of "security," in which "security" was positively correlated with the feeling of "attachment" as well. PAG activity mediates autonomic changes associated with emotions [38]. The PAG is also involved in human maternal behaviors $[18,19]$. This structure is heavily connected with various limbic regions and contains a high density of oxytocin receptors [39]. Oxytocin is a hypothalamic neuropeptide that has been widely implicated in the regulation of positive social interactions, social bonding, and maternal responsiveness in several mammalian species, including humans $[12,40]$.

In the visual with tactile session, several brain regions that have been identified in the human attachment system were significantly activated. However, there was no significant activity of these regions in the visual session. Moreover, among these brain regions, the PAG particularly showed a significant interaction between conditions and sessions, and its differential activity for the preferred versus nonpreferred cosmetics was significantly more activated in the visual with tactile session than in the visual session. This result might indicate that in the visual with tactile session, the preferred cosmetics raised the level of oxytocin in the PAG, whereas the non-preferred ones did not. These results represent the importance of tactile information processing (touch) in attachment to cosmetics. Skin-to-skin contact is one of the earliest communication channels promoting attachment between the infant and the caregiver [9]. Behavioral evidence suggests that human social touch is particularly dependent on the emotional bond between individuals [41]. It is also well known that touch triggers the release of oxytocin [33], and parental touch is linked with increased oxytocin levels in parents [42]. Based on these findings, we concluded that tactile information processing may play an important role in attachment to cosmetics, as in the case of attachment in human relationships.

In addition to the brainstem regions, the putamen, posterior hippocampus, and PCC, which have not been identified to be involved in long-term human attachment [14] (Table 2), were also significantly activated. The putamen receives many dopaminergic fibers projections from the SN/VTA and is a dopamine-rich site. It has been shown that the rat homologue of the putamen represents habitual stimulus-response associations [43], and this finding has been shown to extend to humans [44]. Moreover, this region plays a critical role in action-reward associations [45]. Accordingly, the putamen activity in the present study may be involved in habitual behaviors of daily use of one's favorite cosmetics. The hippocampus is involved in memory processing, including memory retrieval, and is also involved in reward processing [46- 
48]. In fact, long-term potentiation in this region is enhanced and prolonged by dopaminergic inputs from the SN/VTA [49]. In addition, the hippocampus is functionally connected with the PCC [50], which is involved in autobiographical memory retrieval when listening to familiar person names as opposed to non-familiar person names [51]. The PCC has been implicated in many other studies involving familiarity $[52,53]$, and those involving self-representation [54-56]. Furthermore, the PCC plays a critical role in regulating the focus of attention [57-59]. Memories are considered to enhance attachment formation through daily physical contact with cosmetics. Indeed, it has been shown that the extent to which a product evoked memory was shown to be positively related to the degree of product attachment and affected the degree of attachment for the product [7]. The PCC was shown here to be involved in the preference irrespective of tactile cues, and its activity positively correlated with activity of each brainstem regions. This result suggests that the brainstem activity is involved in autobiographical memory retrieval and self-referential processes, evoked by the visual with tactile cues of an individual's attachment to cosmetics. Moreover, the right SI activity was positively correlated with each activity of the DRN and PAG, suggesting a role of the $\mathrm{SI}$ in tactile discriminative processing between the preferred and non-preferred cosmetics.

In the present study, we did not confirm whether the same results in the visual with tactile session would be obtained by only the tactile stimulation of an individual's favorite cosmetics, since we had not conducted a solely tactile session. We cannot deny the possibility that only tactile stimulation without any visual information evokes the brainstem and/or memory-related activity. Furthermore, it is insufficient to deduce the general relationships between products and the users, only from the present study. It is necessary to investigate the differences in brain activity, depending on the characteristics of products and sex. To investigate these further, additional fMRI experiments will need to be performed.

\section{Materials And Methods}

\section{Participants}

A total of 20 healthy right-handed women (age [mean \pm standard deviation]: $33.4 \pm 3.5$ years) participated in the present study. All recruited participants were regular users of one of the three face serums of famous luxury brands ( $A, B$, and $C)$, consuming them more than three times per week. These cosmetics were all within the same price-range $(A \sim ¥ 13,500 / 50 \mathrm{~mL} ; B \sim ¥ 13,500 / 60 \mathrm{~mL} ; C \sim ¥ 13,000 / 50 \mathrm{~mL})$. The number of users of each serum was similar ( 7 participants for $A, 7$ for $B$, and 6 for $C$ ), and more than five bottles of the serum ( $5.2 \pm 2.0$ bottles) were used at the time of the fMRI experiment. They had no history of neurological or psychiatric disorders and provided written and oral informed consent to participate in the present study. The Research Ethics Committee of the Shiseido Global Innovation Center approved the present study, and all the experiments were conducted in accordance with the approved guidelines.

\section{Stimuli, trial protocol, and procedure}

We used three types of face serums (A, B, and C) that had different textures and were in bottles with different visual appearances; each participant could clearly discriminate her regular serum from the 
others. The fMRI experiment consisted of two sessions for every participant with two conditions per session: (i) a visual session consisting of the regular-use serum (the participant's preferred cosmetic) and the control (the other non-preferred cosmetics) conditions, repeated twice per condition, and (ii) a visual with tactile session consisting of the preferred cosmetic conditions and the non-preferred cosmetic conditions, twice per condition. Each stimulus was presented for $30 \mathrm{~s}$ (task block) with a $30 \mathrm{~s}$ interval (rest block). The stimulus presentation order was counterbalanced across participants. In the visual session, participants viewed the photo of a face serum bottle as stimulus in the MRI scanner using goggles that allowed the photos to be projected. In the visual with tactile session, participants were applied with the face serum on the back of their left hands, while they viewed the photo of the face serum bottle. The amount of serum applied was $0.2 \mathrm{~mL}$ per task block. A beauty specialist applied the serum on the back of the participant's hand using the fingers and palm of her right hand. She applied it to the skin and moved her hand in a circle, slowly and softly. The speed of movement was approximately $2.5 \mathrm{~s}$ per cycle. The application procedure was the same for all task blocks. During the rest block, she removed the serum from the participants' hand using a warm wet towel.

\section{Subjective evaluations}

After the fMRI experiment, outside the MRI scanner, participants evaluated all the face serums on a visual analog scale (from 0 to 100 points) of six items: "positive feeling of texture," "expectation for skincare effect," "want to buy," "security," "satisfaction," and "attachment" after being applied with the serum in the same manner as they had in the scanner. The average scores of each subjective evaluation were compared between conditions using a paired $t$-test with a significance level of $p=0.01$. In addition, we conducted a multiple regression analysis with "attachment" as the dependent variable and the other items as the independent variables, with a significance level of $p=0.05$ based on the stepwise method. Furthermore, we checked the residuals for the regression analysis by performing the Shapiro-Wilk test of normality with a significance level of $p=0.05$ and calculated the Durbin-Watson statistic for the null hypothesis of no autocorrelation. Statistical analysis was carried out using SPSS software, version 21.0 (SPSS, Inc., Chicago, IL).

\section{fMRI data analysis}

Scanning was conducted with a 3.0T MRI system (Achieva Quasar Dual; Philips Medical Systems, Best, the Netherlands). Blood oxygenation level dependent T2*-weighted MR signals were measured with a gradient echo-planar imaging (EPI) sequence (repetition time $[T R]=3,000 \mathrm{~ms}$, echo time $[T E]=35 \mathrm{~ms}$, flip angle $[\mathrm{FA}]=90^{\circ}$, field of view $[\mathrm{FOV}]=230 \times 230 \mathrm{~mm}^{2}$, scan matrix $=128 \times 128$, total scan time $=492 \mathrm{~s}$, dynamic scans $=164$ volumes, slice thickness $=5 \mathrm{~mm}$, and 23 slices per volume). Image processing was conducted using the statistical parametric mapping software (SPM8, Wellcome Department of Imaging Neuroscience, London, United Kingdom; http://www.fil.ion.ucl.ac.uk/spm/software/spm8). T1-weighted anatomical images were acquired (150 slices, thickness $1.0 \mathrm{~mm}, \mathrm{TE}=2.0 \mathrm{~ms}, \mathrm{TR}=23 \mathrm{~ms}, \mathrm{FOV}=240 \times$ $240 \mathrm{~mm}^{2}, \mathrm{FA}=30^{\circ}$, and matrix size $=240 \times 240$ ). EPIs were spatially realigned, co-registered, and normalized to the Montreal Neurological Institute template. Normalized images were smoothed using an 
$8 \mathrm{~mm}$ full-width half-maximum Gaussian kernel. The data were temporally convolved with a hemodynamic response function and high-pass filtered with a cutoff period of $128 \mathrm{~s}$. Each condition was modeled using a separate regressor, and the second-level analysis was performed. For the ROI analysis, we set the brain regions that had been identified in the previous fMRI studies of human love attachment in relationships [13-15, 26] (Table 1), as a set of spherical ROls (radius $5 \mathrm{~mm}$ ) for the contrast of the preferred cosmetic condition with the non-preferred cosmetic condition in each session, and tested their significance in the differential brain activity between the visual with tactile session and the visual session, by using the SVC test (significance level; $p=0.05$, FWE).

Moreover, we conducted a multiple regression analysis with the score of a subjectively evaluated item that was significantly correlated with a feeling of "attachment" as the dependent variable, and the eigenvariate values of the ROIs that were significant by the SVC test as the independent variables, in each of the visual with tactile and visual sessions, with a significance level of $p=0.05$ based on the step-wise method. In addition, we added the somatosensory-related ROIs \{the right SI (40 -31 59), secondary somatosensory area (SII) (52 -24 20), and posterior insula (PI) (42 -31 21), and the left SII (-58 -20 14)\} identified in our previous studies $[27,28]$ to the above ROIs in order to confirm the tactile effect on the somatosensory-related regions. Next, we conducted $2 \times 2$ (conditions $\times$ sessions) repeated measures analysis of variance for the ROI activity versus baseline in each condition $(p<0.05)$, and compared their activities between the visual with tactile and the visual sessions using a paired $t$-test based on a Bonferroni correction $(p<0.025=0.05 / 2)$ when there was a significant interaction between conditions and sessions. Moreover, we conducted multiple regression analyses with the eigenvariate value of each brainstem region (DRN, PAG and SN/VTA) as the dependent variable, and activities in each of the memory-related ROIs and the somatosensory-related ROIs, based on the step-wise method corrected by Holm method $(p<0.05)$. Furthermore, we checked the residuals for all regression analyses by performing a Shapiro-Wilk test of normality (significance level; $p=0.05$ ) and calculated the $D-W$ statistic for the null hypothesis of no autocorrelation.

\section{Data availability}

Due to the confidentiality agreements with the participants, the data in this study are available only at the Shiseido Global Innovation Center and Tokyo Metropolitan University.

\section{Declarations}

\section{Data availability}

Due to the confidentiality agreements with the participants, the data in this study are available only at the Shiseido Global Innovation Center and Tokyo Metropolitan University.

\section{Acknowledgements}


We would like to thank the participants in this study and Mika Nakayama for applying the skincare essence as a beauty specialist. The present work was entirely funded by the Shiseido Global Innovation Center and Tokyo Metropolitan University.

\section{Author contributions}

Y.K., M.N., H.I., M.S., and N.H. contributed to the planning and execution of the present study and discussion of the present results. H.I., M.S., and N.H. contributed to the recruiting of the participants. Y.K. and M.N. contributed to data analyses and writing.

\section{Competing interests}

The authors report no conflicts of interest.

\section{References}

1. Belk, R. W. Possessions and the extended self. Consum. Res. 15, 139-168 (1988).

2. Kleine, S. S., Kleine, R. E. \& Allen, C. T. How is a possession "me" or "not me"? Characterizing types and an antecedent of material possession attachment. Consum. Res. 22, 327-343 (1995).

3. Ball, A. D. \& Tasaki, L. H. The role and measurement of attachment in consumer behavior. Consum. Psychol. 1, 155-172 (1992).

4. Wallendorf, M. \& Arnould, E. J. "My favorite things": a cross-cultural inquiry into object attachment, possessiveness, and social linkage. Consum. Res. 14, 531-547 (1988).

5. Mugge, R., Schifferstein, H. N. J. \& Schoormans, J. P. L. Product attachment and product lifetime: the role of personality congruity and fashion. European Advances in Consumer Research. 7, 460-467 (2005).

6. Schultz, S. E., Kleine, R. E., \& Kernan, J. B. "These are a few of my favorite things." Toward an explication of attachment as a consumer behavior construct. Consum. Res. 16, 359-366 (1989).

7. Schifferstein, H. N. J. \& Zwartkruis-Pelgrim, E. P. H. Consumer-product attachment: measurement and design implications. J. Des. 2, 1-14 (2008).

8. Antill, J. K. Sex-role complementarity versus similarity in married couples. Pers. Soc. Psychol. 45, 145-155 (1983).

9. Mclntyre, K. P., Mattingly, B. A. \& Lewandowski, W. Self-concept clarity and romantic relationships in Self-concept clarity (eds. Lod-Smith, J., Demarree, K. G.) 107-124 (Springer, 2017).

10. Sirgy, M. J. Self-concept in consumer behavior: a critical review. Consum. Res. 9, 287-300 (1982).

11. Hertenstein, M. J., Verkamp, J. M., Kerestes, A. M. \& Holmes, R. M. The communicative functions of touch in humans, nonhuman primates, and rats: a review and synthesis of the empirical research. Soc. Gen. Psychol. Monogr. 132, 5-94 (2006).

12. Kikuchi, Y., Noriuchi, M. The romantic brain: secure attachment activates the brainstem centers of well-being in Emotional engineering, 8 (ed. Fukuda, S.), 189-198 (Springer, Cham, 2020). 
13. Aron, A. et al. Reward, motivation, and emotion systems associated with early-stage intense romantic love. Neurophysiol. 94, 327-337 (2005).

14. Acevedo, B. P., Aron, A., Fisher, H. E. \& Brown, L.L. Neural correlates of long-term intense romantic love. Cogn. Affect. Neurosci. 7, 145-59 (2012).

15. Kikuchi, Y. et al. Brainstem activity predicts attachment-related anxiety. Neuropsychiatry. 8, 324-334 (2018).

16. Stárka, L. Endocrine factors of pair bonding. Med. Rep. 108, 297-305 (2007).

17. Berscheid, E. Love in the fourth dimension. Rev. Psychol. 61, 1-25 (2010).

18. Bartels, A. \& Zeki, S. The neural correlates of maternal and romantic love. Neuroimage. 21, 11551166 (2004).

19. Noriuchi, M., Kikuchi, Y. \& Senoo, A. The functional neuroanatomy of maternal love: mother's response to infant's attachment behaviors. Psychiatry. 63, 415-423 (2008).

20. Kikuchi, Y., Noriuchi, M. The neuroscience of maternal love. Neuroscience Communications. 1, e991 (2015).

21. Kikuchi, Y., Noriuchi, M. Neural basis of maternal love as a vital human emotion in Emotional engineering, 4 (ed. Fukuda, S.) 189-198 (Springer, Cham, 2016).

22. Noriuchi, M., Kikuchi, Y., Mori, K. \& Kamio, Y. The orbitofrontal cortex modulates parenting stress in the maternal brain. Rep. 9, 1658 (2019).

23. Sevastian, V. New directions in understanding the decision-making process: neuroeconomics and neuromarketing. Procedia Behav. Sci. 127, 758-762 (2014).

24. Frost, R.O., Hartl, T.L., Christian, R., \& Williams, N. The value of possessions in compulsive hoarding: patterns of use and attachment. Res. Ther. 33, 897-902 (1995).

25. Tolin, D.F. et al. Neural mechanisms of decision making in hoarding disorder. Gen. Psychiatry. 69, 832-841 (2012).

26. Bartels, A., Zeki, S. The neural basis of romantic love. 27, 3829-3834 (2000).

27. Shirato, M., Kikuchi, Y., Machida, A., Inoue, T., Noriuchi, M. Gentel touch opens the gate to the primary somatosensory cortex. 8, 1696-1707 (2018).

28. Hirao, N., Noriuchi, M., Isobe, H., Kikuchi, Y. Luxury cues of cream heighten the reward value of its tactile experience. Cosmet. Sci. (in press).

29. Sroufe, L. A. \& Waters, E. Attachment as an organizational construct. Child Development. 48, 11841199 (1977).

30. Delgado, M. R., Locke, H. M., Stenger, V. A. \& Fiez, J. A. Dorsal striatum responses to reward and punishment: effects of valence and magnitude manipulations. Affect. Behav. Neurosci. 3, 27-38 (2003).

31. O'oherty, J. et al. Dissociable roles of ventral and dorsal striatum in instrumental conditioning. 304, 452-454 (2004). 
32. Camara, E., Rodriguez-Fornells, A., Ye, Z. \& Münte, T. F. Reward networks in the brain as captured by connectivity measures. Neurosci. 3, 350-362 (2009).

33. Cascio, C. J., Moore, D. \& McGlone, F. Social touch and human development. Cogn. Neurosci. 35, 5-11 (2019).

34. Micallef, J. \& Blin, O. Neurobiology and clinical pharmacology of obsessive-compulsive disorder. Neuropharmacol. 24, 191-207 (2001).

35. Young, S. N. \& Leyton, M. The role of serotonin in human mood and social interaction. Insight from altered tryptophan levels. Biochem. Behav. 71, 857-865 (2002).

36. Bailer, U.F. et al. Serotonin transporter binding after recovery from eating disorders. Psychopharmacology (Berl). 195, 315-324 (2007).

37. Leonardo, E.D. \& Hen, R. Genetics of affective and anxiety disorders. Rev. Psychol. 57, 117-137 (2006).

38. Grenhoff, J., Nisell, M., Ferré, S., Aston-Jones, G. \& Svensson, T. H. Noradrenergic modulation of midbrain dopamine cell firing elicited by stimulation of the locus coeruleus in the rat. Neural Transm. Gen. Sect. 93, 11-25 (1993).

39. Jenkins, J. S., Ang, V. T., Hawthorn, J., Rossor, M. N. \& Iversen, L. L. Vasopressin, oxytocin and neurophysins in the human brain and spinal cord. Brain Res. 291, 111-117 (1984).

40. Olazábal, D. E. \& Young, L. J. Oxytocin receptors in the nucleus accumbens facilitate "spontaneous" maternal behavior in adult female prairie voles. Neuroscience. 141, 559-568 (2006).

41. Willis F. N. \& Briggs, L. F. Relationship and touch in public settings. Nonverbal Behav. 16, 55-64 (1992).

42. Feldman, R., Gordon, I., Schneiderman, I., Weisman, O. \& Zagoory-Sharon, O. Natural variations in maternal and paternal care are associated with systematic changes in oxytocin following parentinfant contact. 35, 1133-1141 (2010).

43. Yin, H. H. \& Knowlton, B. J. The role of the basal ganglia in habit formation. Rev. Neurosci. 7, 464-476 (2006).

44. Tricomi, E., Balleine, B. W. \& O'Doherty, J. P. A specific role for posterior dorsolateral striatum in human habit learning. J. Neurosci. 29, 2225-2232 (2009).

45. Haruno, M., Kawato, M. Differential neural correlates of reward expectation and reward expectation error in the putamen and caudate nucleus during stimulus-action-reward association learning. Neurophysiol. 95, 948-959 (2006).

46. Viard, A. et al. Hippocampal activation for autobiographical memories over the entire lifetime in healthy aged subjects: an fMRI study. Cortex. 17, 2453-2467 (2007).

47. Oba, K., Noriuchi, M., Atomi, T., Moriguchi, Y. \& Kikuchi, Y. Memory and reward systems coproduce 'nostalgic' experiences in the brain. Cogn. Affect Neurosci. 11, 1069-1077 (2016).

48. Kikuchi, Y. \& Noriuchi, M. The nostalgic brain: its neural basis and positive emotional role in resilience in Emotional engineering, Vol. 5 (ed. Fukuda, S.) 43-53 (Springer, Cham 2017). 
49. Kauer, J.A., Malenka, R.C. \& Nicoll, R.A. A persistent postsynaptic modification mediates long-term potentiation in the hippocampus. Neuron. 1, 911-917 (1988).

50. Poppenk, J. et al. Why is the meaning of a sentence better remembered than its form? An fMRI study on the role of novelty-encoding processes. Hippocampus. 18, 909-918 (2008).

51. Maddock, R.J., Garrett, A.S. \& Buonocore, M.H. Remembering familiar people: the posterior cingulate cortex and autobiographical memory retrieval. 104, 667-676 (2001).

52. Hornberger, M., Rugg, M.D., Henson, R.N. fMRI correlates of retrieval orientation. 44, 1425-1436 (2006).

53. Wagner, A.D., Shannon, B.J., Kahn, I., Buckner, R.L. Parietal lobe contributions to episodic memory retrieval. Trends Cogn. Sci. 9, 445-453 (2005).

54. Addis, D.R., Wong, A.T., Schacter, D.L. Remembering the past and imagining the future: common and distinct neural substrates during event construction and elaboration. 45, 1363-1377 (2007).

55. Hassabis, D., Kumaran, D., Maguire, E.A. Using imagination to understand the neural basis of episodic memory. Neurosci. 27, 14365-14374 (2007).

56. Vogt, B.A., Vogt, L., Laureys, S. Cytology and functionally correlated circuits of human posterior cingulate areas. 29, 452-466 (2006).

57. Gusnard, D.A., Raichle, M.E \& Raichle, M.E. Searching for a baseline: functional imaging and the resting human brain. Rev. Neurosci. 2, 685-694 (2001).

58. Hampson, M., Driesen, N. R., Skudlarski, P., Gore, J. C. \& Constable, R. T. Brain connectivity related to working memory performance. Neurosci. 26, 13338-13343 (2006).

59. Hahn, B., Ross, T. J. \& Stein, E.A. Cingulate activation increases dynamically with response speed under stimulus unpredictability. Cortex. 17, 1664-1671 (2007).

\section{Tables}

Table 1. Summary of the previous fMRI studies of attachment in human relationships. 


\begin{tabular}{|c|c|c|c|}
\hline fMRI study & $\begin{array}{l}\text { Numbers of } \\
\text { subjects }\end{array}$ & Age & Duration of relationships \\
\hline \multirow{2}{*}{$\begin{array}{l}\text { Aron et al, } \\
2005 \text { [13] }\end{array}$} & \multirow{2}{*}{$\begin{array}{l}17 \text { subjects ( } 10 \\
\text { females, } 7 \text { males) }\end{array}$} & $18-26$ years & \multirow{2}{*}{$\begin{array}{l}1-17 \text { months, mean }=7 \text { months, } \\
\text { median }=7 \text { months }\end{array}$} \\
\hline & & $\begin{array}{l}\text { (mean }=20.6 \text { years, } \\
\text { median }=21 \text { years) }\end{array}$ & \\
\hline \multirow{2}{*}{$\begin{array}{l}\text { Bartels \& } \\
\text { Zeki, } 2000 \\
\text { [26] }\end{array}$} & \multirow{2}{*}{$\begin{array}{l}17 \text { subjects ( } 11 \\
\text { females, } 6 \text { males) }\end{array}$} & $21-37$ years & \multirow{2}{*}{$\begin{array}{l}\text { mean }=2.4 \text { years, s.d. }=1.7 \\
\text { years, median }=2.3 \text { years }\end{array}$} \\
\hline & & $\begin{array}{l}(\text { mean }=24.5 \text { years, } \\
\text { median }=23 \text { years })\end{array}$ & \\
\hline \multirow{2}{*}{$\begin{array}{l}\text { Kikuchi et al, } \\
2017 \text { [15] }\end{array}$} & \multirow{2}{*}{$\begin{array}{l}17 \text { subjects ( } 17 \\
\text { males) }\end{array}$} & $22-43$ years & \multirow{2}{*}{$\begin{array}{l}11 \text { subjects married } \\
\text { (marital duration }=5.2 \pm 5.9 \\
\text { years, age } 35.0 \pm 6.8 \text { years) } \\
6 \text { subjects not married } \\
\text { (relation duration }=1.7 \pm 1.3 \\
\text { years, age } 24.8 \pm 3.7 \text { years) }\end{array}$} \\
\hline & & $\begin{array}{l}(\text { mean }=31.4 \text { years, } \\
\text { s.d. }=7.7 \text { years })\end{array}$ & \\
\hline \multirow{2}{*}{$\begin{array}{l}\text { Acevedo et } \\
\text { al, } 2011[14]\end{array}$} & \multirow{2}{*}{$\begin{array}{l}17 \text { subjects ( } 10 \\
\text { females, } 7 \text { males) }\end{array}$} & $39-67$ years & \multirow{2}{*}{$\begin{array}{l}\text { All married } 10-29 \text { years, } \\
\text { mean }=21 \text { years, s.d. }=5.9 \text { years }\end{array}$} \\
\hline & & $\begin{array}{l}\text { (mean }=52.9 \text { years, } \\
\text { s. } d=8.9 \text { years) }\end{array}$ & \\
\hline
\end{tabular}

s.d., standard deviation. Data are presented as meanstandard deviation.

Table 2. The differential activity of different brain regions on using the preferred vs. the non-preferred cosmetics. 


\begin{tabular}{|c|c|c|c|c|c|c|c|}
\hline \multirow[t]{2}{*}{ L/R } & \multirow[t]{2}{*}{$\begin{array}{l}\text { Brain } \\
\text { region }\end{array}$} & \multicolumn{3}{|c|}{ MNI } & \multicolumn{2}{|c|}{$\begin{array}{l}\text { Session p- } \\
\text { values }\end{array}$} & \multirow[t]{2}{*}{ fMRI study (ROIs) } \\
\hline & & $\mathbf{x}$ & y & $\mathbf{z}$ & visual & $\begin{array}{l}\text { visual } \\
+ \\
\text { tactile }\end{array}$ & \\
\hline $\mathrm{R}$ & PCC & 3 & -22 & 29 & 0.375 & $0.018 *$ & $\begin{array}{l}\text { Aron et al, } 2005 \text { [13] (7 months); Bartels et } \\
\text { al, } 2000 \text { [26] (2.4 years) }\end{array}$ \\
\hline $\mathrm{R}$ & putamen & 29 & 2 & -3 & 0.175 & $0.028 *$ & \multirow[t]{3}{*}{ Bartels et al, 2000 [18] (2.4 years) } \\
\hline L & $\begin{array}{l}\text { posterior } \\
\mathrm{HC}\end{array}$ & -40 & -36 & -12 & 0.517 & $0.027 *$ & \\
\hline $\mathrm{R}$ & $\begin{array}{l}\text { posterior } \\
\mathrm{HC}\end{array}$ & 40 & -31 & -4 & 0.464 & $0.021 *$ & \\
\hline L & PCC & -4 & -22 & 32 & 0.439 & $0.025^{\star}$ & \multirow[t]{2}{*}{ Kikuchi et al, 2017 [15] (5.6 years) } \\
\hline $\mathrm{R}$ & PCC & 6 & -16 & 32 & 0.311 & $0.009 *$ & \\
\hline $\mathrm{R}$ & DRN & 6 & -32 & -24 & 0.575 & $0.041 *$ & \multirow{2}{*}{$\begin{array}{l}\text { Acevedo et al, } 2011 \text { [14] (21.5 years); } \\
\text { (DRN: Kikuchi et al, 2017 [15] (5.6 } \\
\text { years)/PAG: Kikuchi et al, 2017 [15] (5.6 } \\
\text { years), }\end{array}$} \\
\hline $\mathrm{R}$ & PAG & 3 & -35 & -28 & 0.529 & $0.034 *$ & \\
\hline $\mathrm{R}$ & SN/VTA & 4 & -20 & -16 & 0.364 & $0.047 *$ & Bartels et al, 2004 [18] (maternal love)) \\
\hline
\end{tabular}

Significant probability of each ROI activity is shown in each session (SVC, $p<0.05 \mathrm{FWE}$ ). ${ }^{*}$ represents significance

SVC, small volume correction; FWE, family-wise error; MNI, Montreal Neurological Institute coordinates; DRN, dorsal raphe nucleus;

SN, substantia nigra; VTA, ventral tegmental area; PAG, periaqueductal gray; PCC, posterior cingulate cortex; HC, hippocampus.

\section{Figures}




\section{Subjective evaluation}

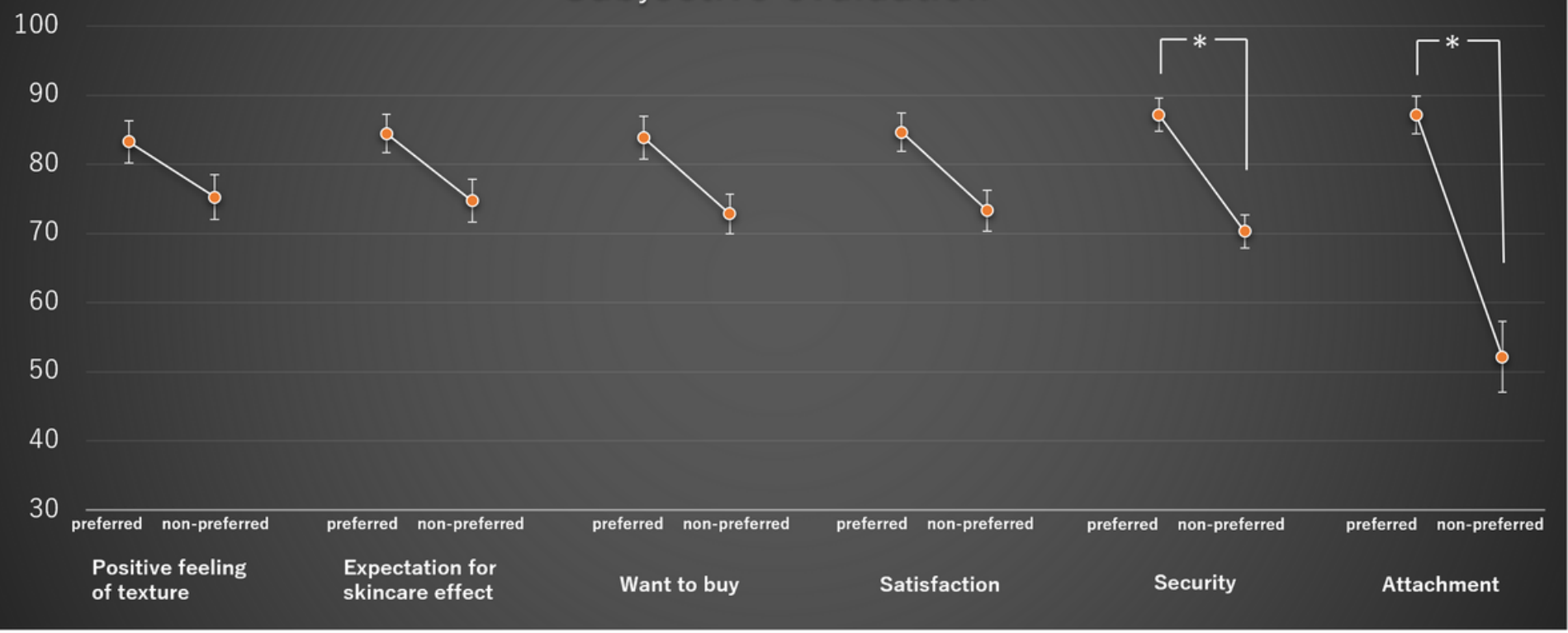

\section{Figure 1}

Comparisons of subjective evaluations between the preferred cosmetics vs. the non-preferred cosmetics for each of the six items. An asterisk $\left(^{*}\right)$ represents significance as assessed by a paired t-test $(p<0.01)$. 


\section{Security vs. Attachment}
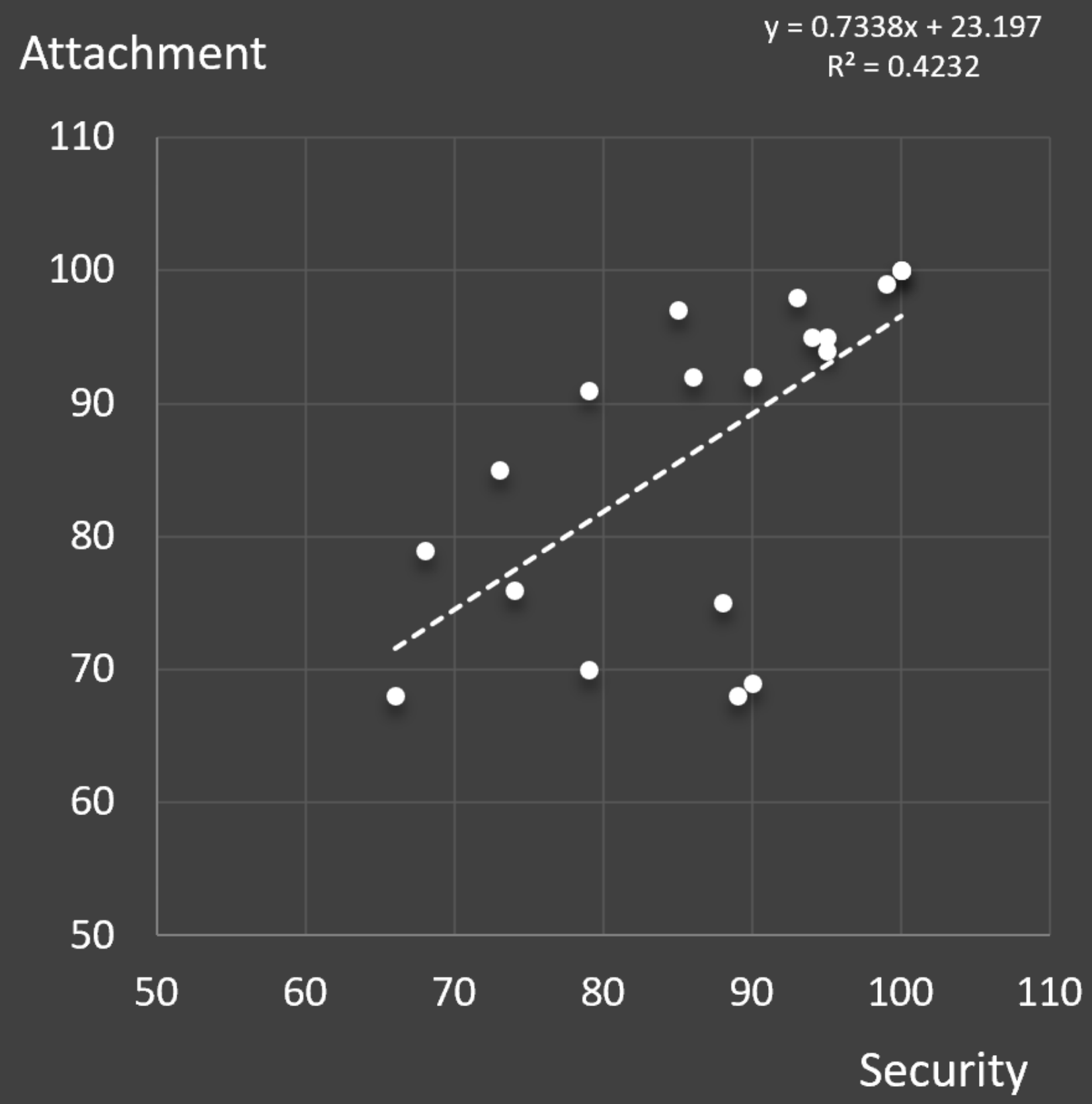

\section{Figure 2}

Correlation between the subjective evaluation items, "attachment" and "security," as assessed by the multiple regression analysis performed by designating the former item as the independent variable, and the other five items as the dependent variables, based on the step-wise method $(p<0.05)$. 


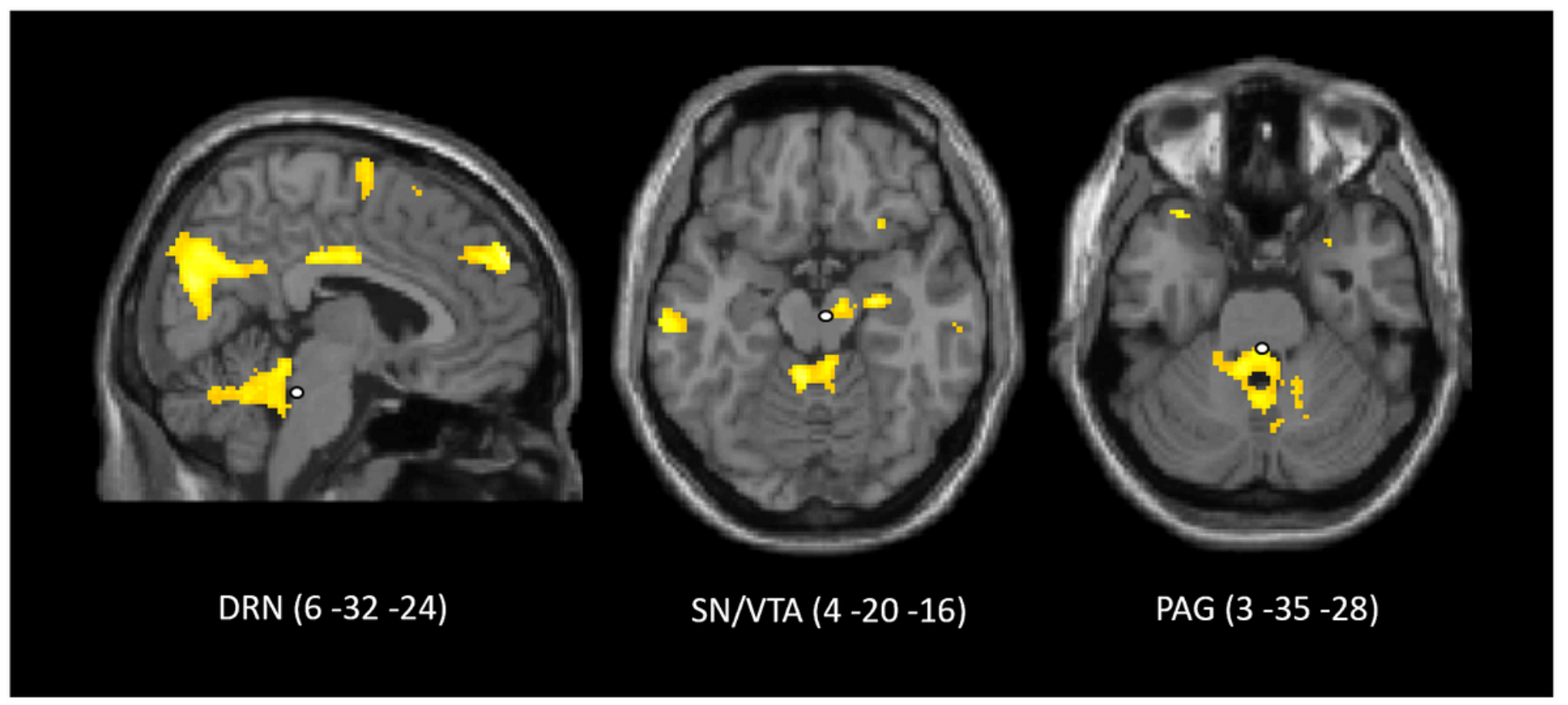

\section{Figure 3}

The brainstem regions of interest (white circle) superimposed on the whole brain activity $(p<0.01$, Clusters > 10, for illustration). DRN, dorsal raphe nucleus; SN, substantia nigra; VTA, ventral tegmental area; PAG, periaqueductal gray.

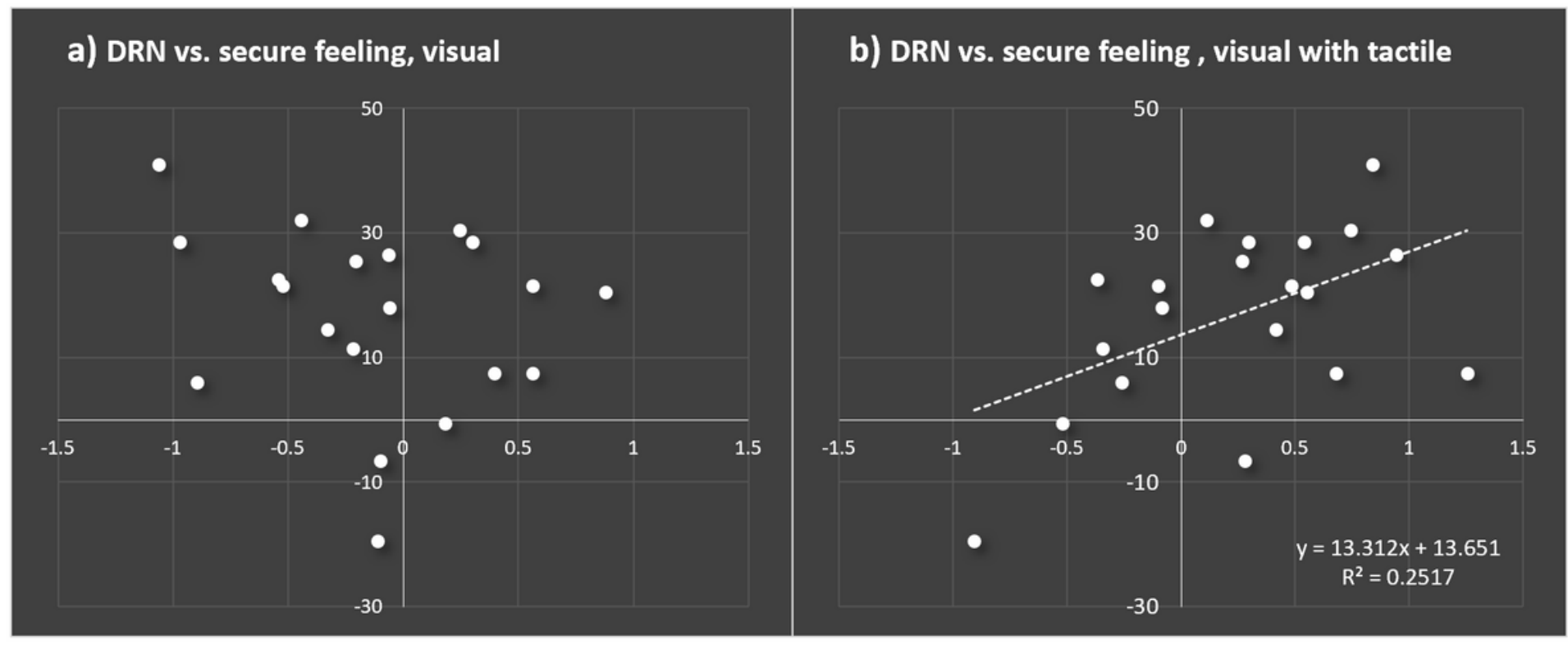

\section{Figure 4}

The correlations between the differential DRN activity (horizontal axis) and score of "security" feeling (vertical axis) for the preferred cosmetics vs. non-preferred ones, in the visual session (visual) (a) and the visual with tactile session (visual with tactile) (b). DRN, dorsal raphe nucleus. 

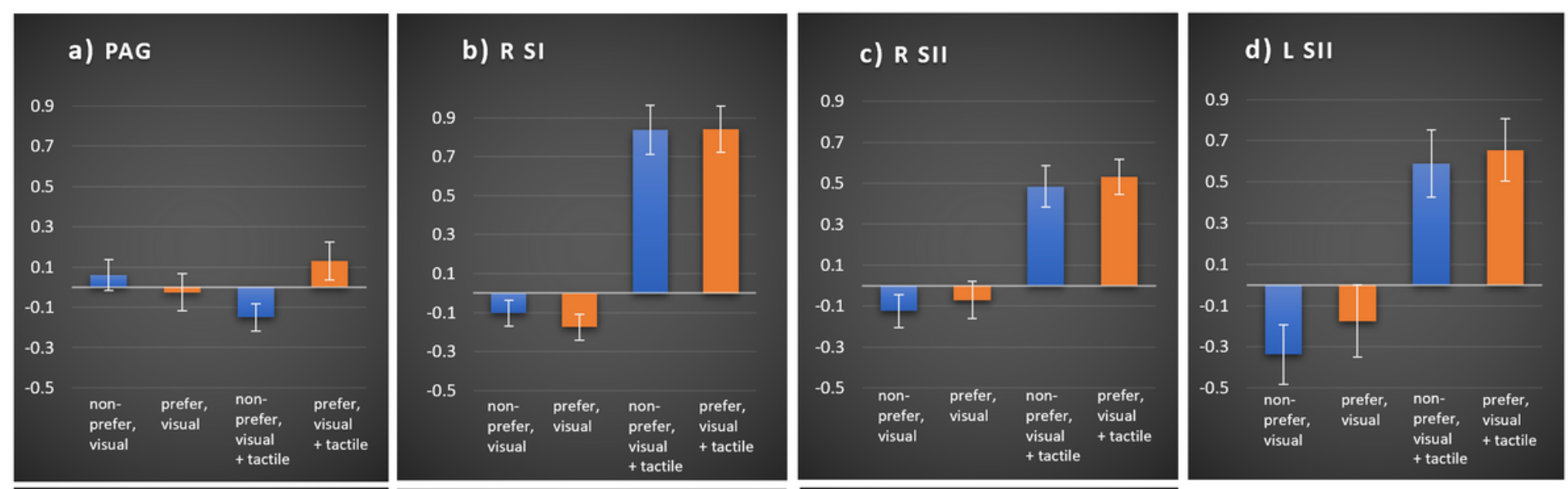

e) R PI

\section{f) $L$ PCC}

g) R PCC
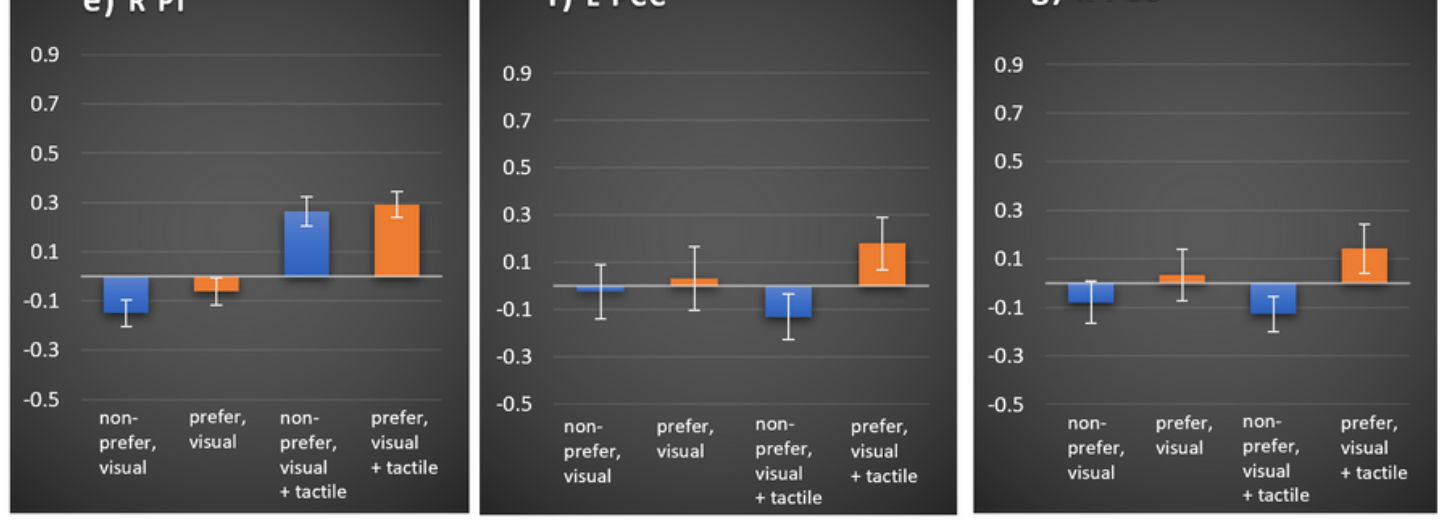

\section{Figure 5}

Beta values (vertical line) of the regions of interest in the non-preferred and preferred cosmetics (visual; visual session), and the non-preferred and preferred cosmetics (visual + tactile; visual with tactile session). a) PAG (3 -35 -28), b) R SI (40 -31 59), c) R SII (52 -24 20), d) L SII (-58 -20 14), e) R PI (42 -31 $21)$, f) L PCC (-4 -22 32), and g) R PCC (6 -16 32). SI, primary somatosensory cortex; SIl, secondary somatosensory cortex; PI, posterior insula; PCC, posterior cingulate cortex, PAG, periaqueductal grey. 
a) R PCC vs. DRN, visual with tactile

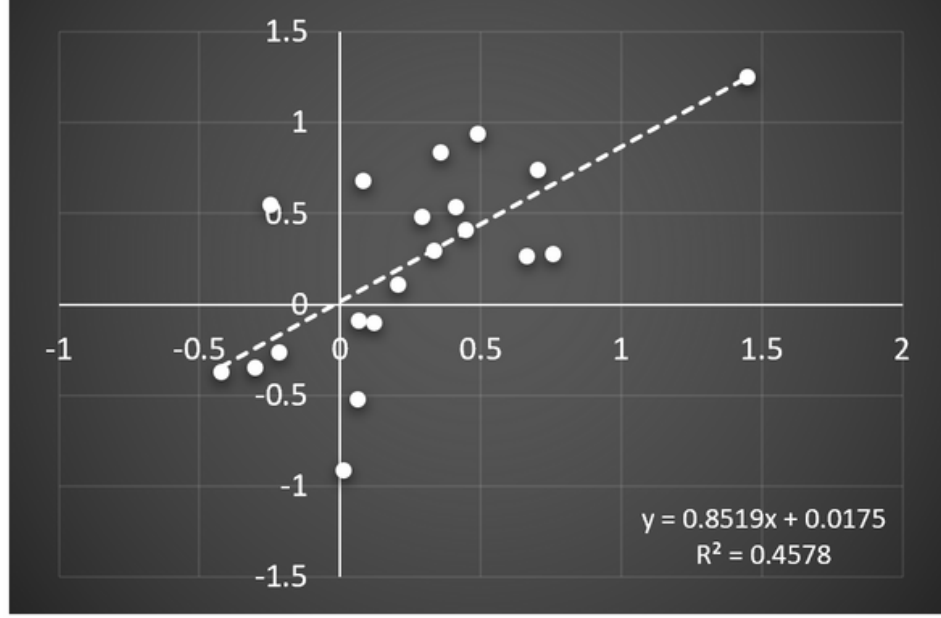

c) R PCC vs. PAG, visual with tactile

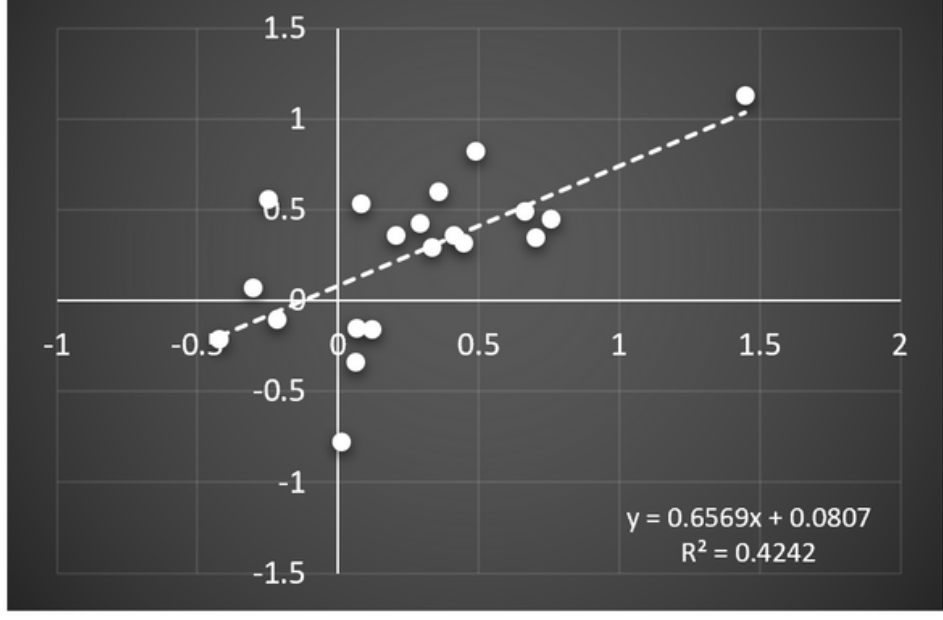

b) SI vs. DRN, visual with tactile

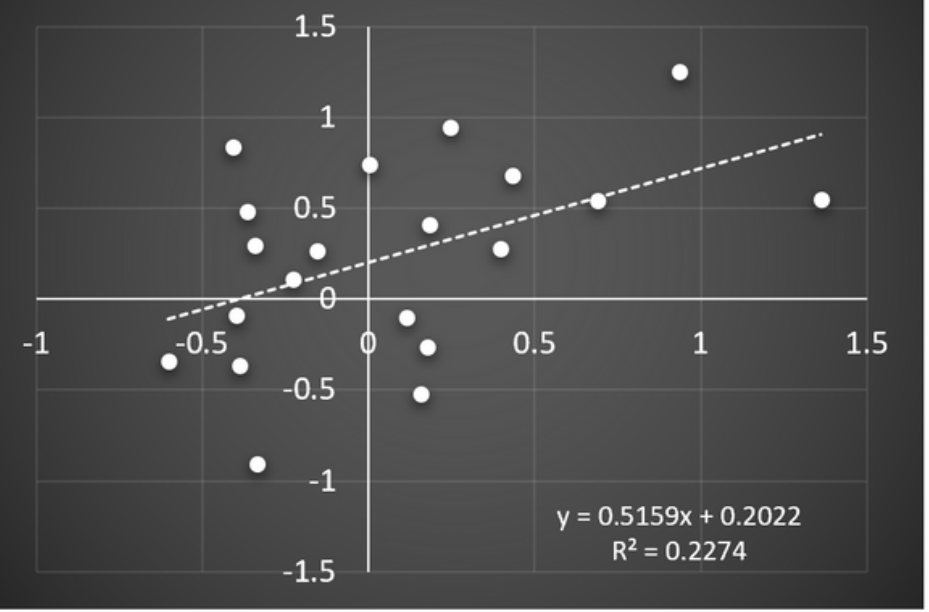

d) SI vs, PAG, visual with tactile

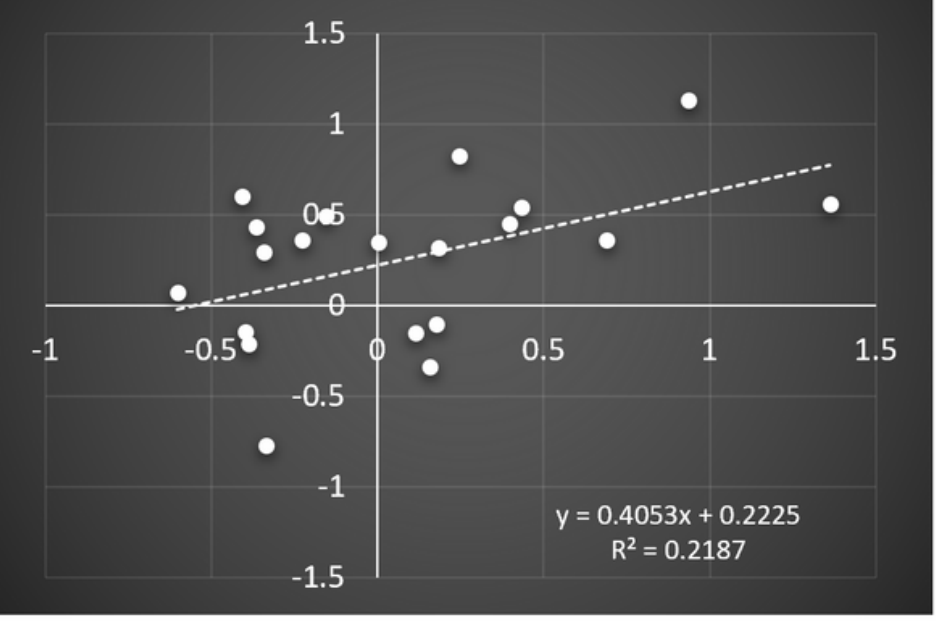

\section{Figure 6}

The correlations of the differential DRN activity (vertical axis) with PCC (6 -16 32) activity (horizontal axis) (a) and those with SI (40-31 59) (b), for the preferred cosmetics versus non-preferred ones in the visual with tactile session, and the correlations of the differential PAG activity (vertical axis) with PCC (6 -16 32) activity (horizontal axis) (c) and those with SI (40-31 59) (d), for the preferred cosmetics versus non-preferred ones in the visual with tactile session. DRN, dorsal raphe nucleus; PAG, periaqueductal gray; PCC, posterior cingulate cortex; SI, primary somatosensory cortex. 